OPEN ACCESS

Edited by:

Pasquale Esposito,

University of Genoa, Italy

Reviewed by:

Moshe Levi,

Georgetown University, United States

Ashish Verma

Brigham and Women's Hospital and Harvard Medical School,

United States

*Correspondence:

Etty Kruzel-Davila

ettyk@gmc.gov.il;

etty.kruzel@gmail.com

tThese authors have contributed equally to this work

$\mp$ Deceased

Specialty section: This article was submitted to Nephrology,

a section of the journal

Frontiers in Medicine

Received: 31 May 2021 Accepted: 05 August 2021 Published: 27 August 2021

Citation:

Kruzel-Davila E, Sankofi BM, Kubi Amos-Abanyie E, Ghansah A, Nyarko A, Agyemang $S$ Awandare GA, Szwarcwort-Cohen $M$, Reiner-Benaim A, Hijazi B, Ulasi I, Raji YR, Boima V, Osafo C, May Adabayeri V, Matekole M,

Olanrewaju TO, Ajayi S, Mamven M, Antwi S, Ademola AD, Plange-Rhule J, Arogundade F, Akyaw PA, Winkler CA,

Salako BL, Ojo A, Skorecki K, Adu D and the H3Africa Kidney Disease Research Network Investigators (2021) HIV Viremia Is Associated With APOL1 Variants and Reduced JC-Viruria. Front. Med. 8:718300. doi: 10.3389/fmed.2021.718300

\section{HIV Viremia Is Associated With APOL1 Variants and Reduced JC-Viruria}

\author{
Etty Kruzel-Davilaa, ${ }^{1,2 *}$, Barbara Mensah Sankofi ${ }^{3,4 t}$, Ernestine Kubi Amos-Abanyie ${ }^{3}$, \\ Anita Ghansah ${ }^{3}$, Alexander Nyarko ${ }^{3}$, Seth Agyemang ${ }^{4,5}$, Gordon A. Awandare ${ }^{4}$, \\ Moran Szwarcwort-Cohen ${ }^{6}$, Anat Reiner-Benaim ${ }^{6}$, Basem Hijazi ${ }^{7}$, Ifeoma Ulasi ${ }^{8}$, \\ Yemi Raheem Raji ${ }^{9}$, Vincent Boima ${ }^{5}$, Charlotte Osafo ${ }^{5}$, Victoria May Adabayeri ${ }^{5}$, \\ Michael Matekole ${ }^{5}$, Timothy O. Olanrewaju ${ }^{10}$, Samuel Ajayi ${ }^{9}$, Manmak Mamven ${ }^{11}$, \\ Sampson Antwi ${ }^{10}$, Adebowale D. Ademola ${ }^{9}$, Jacob Plange-Rhule ${ }^{10 \neq}$, Fatiu Arogundade ${ }^{12}$, \\ Priscilla Abena Akyaw ${ }^{3}$, Cheryl A. Winkler ${ }^{13}$, Babatunde L. Salako ${ }^{9}$, Akinlolu Ojo ${ }^{14}$, \\ Karl Skorecki ${ }^{1,6,7 t}$, Dwomoa Adu ${ }^{5+}$ and \\ the H3Africa Kidney Disease Research Network Investigators
}

\begin{abstract}
${ }^{1}$ Rappaport Faculty of Medicine, Technion Israel Institute of Technology, Haifa, Israel, ${ }^{2}$ Nephrology Department, Rambam Health Care Campus, Haifa, Israel, ${ }^{3}$ College of Health Sciences, Noguchi Memorial Institute for Medical Research, University of Ghana, Accra, Ghana, ${ }^{4}$ West African Centre for Cell Biology of Infectious Pathogens, College of Basic and Applied Sciences, University of Ghana, Accra, Ghana, ${ }^{5}$ University of Ghana Medical School, College of Health Sciences, University of Ghana, Accra, Ghana, ${ }^{6}$ Rambam Health Care Campus, Haifa, Israel, ${ }^{7}$ Azrieli Faculty of Medicine, Bar-llan University, Safed, Israel, ${ }^{8}$ Department of Medicine, College of Health Sciences University of Nigeria, Enugu, Nigeria, ${ }^{9}$ Department of Medicine, University of Ibadan, Ibadan, Nigeria, ${ }^{10}$ Department of Medicine, Kwame Nkrumah University of Science and Technology, Kumasi, Ghana, ${ }^{11}$ Department of Medicine, University of Abuja, Abuja, Nigeria, ${ }^{12}$ Obafemi Awolowo University, lle-lfe, Nigeria, ${ }^{13}$ Department of Medicine, Frederick National Laboratory for Cancer Research (NIH). Frederick, MD, United States, ${ }^{14}$ School of Medicine, University of Kansas Medical Center, Kansas City, KS, United States
\end{abstract}

Variants in the Apolipoprotein L1 (APOL1) gene (G1-rs60910145, rs73885319, G2-rs71785313) are common in Africans and in individuals of recent African ancestry and are associated with an increased risk of non-diabetic chronic kidney disease (CKD) and in particular of HIV associated nephropathy (HIVAN). In light of the significantly increased risk of HIVAN in carriers of two APOL 1 risk alleles, a role in HIV infectivity has been postulated in the mechanism of $A P O L 1$ associated kidney disease. Herein, we aim to explore the association between HIV viremia and APOL1 genotype. In addition, we investigated interaction between BK and JC viruria, CKD and HIV viremia. A total of 199 persons living with HIV/AIDS (comprising 82 CKD cases and 117 controls) from among the participants in the ongoing Human Heredity and Health in Africa (H3Africa) Kidney Disease Research Network case control study have been recruited. The two APOL 1 renal risk alleles (RRA) genotypes were associated with a higher risk of CKD (OR 12.6, 95\% Cl 3.89-40.8, $p<0.0001$ ). Even a single APOL1 RRA was associated with CKD risk (OR 4.42, 95\% Cl 1.49-13.15, $p=0.007)$. The 2 APOL1 RRA genotypes were associated with an increased probability of having HIV viremia (OR 2.37 95\% Cl 1.0-5.63, $p=0.05$ ). HIV viremia was associated with increased CKD risk (OR 7.45, 95\% Cl 1.66-33.35, $P=0.009)$ and with a significant reduction of $\mathrm{JC}$ virus urine shedding (OR $0.35,95 \%$ 
Cl 0.12-0.98, $p=0.046)$. In contrast to prior studies, JC viruria was not associated with CKD but was restricted in patients with HIV viremia, regardless of CKD status. These findings suggest a role of $A P O L 1$ variants in HIV infectivity and emphasize that JC viruria can serve as biomarker for innate immune system activation.

Keywords: APOL1, HIV viremia, JC viruria, BK viruria, innate immune, kidney disease

\section{INTRODUCTION}

Two variants at the APOL1 gene, encoding Apolipoprotein L1, account for more than $70 \%$ of the increased risk for non-diabetic chronic kidney disease (CKD) in individuals of African ancestry (1-3). The ancestral non-renal risk allele has been designated G0 and the two risk alleles (renal risk alleles, RRA) have been designated as G1 (encoding S342G and I384M substitutions) and G2 (encoding the combined N388 and Y389 deletions), respectively $(1,3)$. These variants have risen to high allele frequency due to a dominant selective advantage that restores trypanolytic activity against $T$. $b$. rhodesiense (G2) and confers protection from active illness caused by T. b. gambiense (G1) $(1,4-6)$. Unexpectedly, the G2 genotype is associated with active T. b. gambiense infection (5). It is an enigma why some of the highest frequencies of $\mathrm{G} 2$ are also found in regions of West Africa where T. b. gambiense is endemic, despite the observed G2 association with symptomatic chronic sleeping sickness. This raises the likelihood of a broader role in pathogen resistance by the RRA, extending beyond trypanosomes (4-6). Therefore, the protective role of APOL1 variants in various infectious diseases is under continued extensive investigation. HIV infection deserves special consideration in regard to modulation of HIV infectivity by APOL1 variants. In light of the significantly increased risk of HIV associated nephropathy (HIVAN) in carriers of two APOL1 RRA $(2,7)$, a role in HIV infectivity has been postulated. In vitro studies have demonstrated that G0 APOL1 restricts HIV replication in macrophages and differentiated monocytes (8). APOL1 was also identified as one of the HIV restriction proteins, by using genome-wide scans for human genes sharing molecular and evolutionary signatures of known restriction factors. These findings were also validated using in vitro studies demonstrating anti-HIV- activity (9). In addition, the presence of RRA but not G0 APOL1 led to persistence of HIV infection in human podocytes in synergy with IL1beta (10). Recently, a genetic association study (ALIVE - AIDS Link to the Intravenous Experience cohort) revealed no evident association of APOL1 RRA with HIV infection acquisition, viral load or disease progression, in antiretroviral therapy (ART) naïve patients (11). That study examined HIV natural history cohorts enrolling African Americans prior to the ART era. The large number of treatment-naïve seroconverters made it a choice cohort for unbiased exploration of HIV-related outcomes. Herein, we explored the association of HIV viremia and CKD with APOL1 variants in participants recruited from HIV clinics in Africa. All the participants were attending HIV clinics were likely to have received ART, but we cannot be certain of adherence. We also examined the association between JC and $\mathrm{BK}$ viruria in all participants, in light of previous findings demonstrating reduced JC viruria in $\mathrm{CKD}$ patients and the expected increased BK urine shedding in immunocompromised HIV infected patients (12-17).

\section{MATERIALS AND METHODS}

\section{Ethics Statement}

Ethical approval for the study was obtained from all the Institutional Review Boards of each participating institution as well as the lead clinical center at the University of Ghana (Ghana Health Service Ethics Review Committee) who approved the study protocols. Written informed consent was obtained from all study participants.

\section{Study Participants}

Age and sex matched Africans from Ghana and Nigeria with HIV infection were recruited as part of the H3Africa Kidney Disease Research Network, from 2013 to 2018.

The study group comprises 82 individuals with CKD and 117 individuals with normal kidney function. The estimated glomerular filtration rate (eGFR) was computed using the creatinine-based Chronic Kidney Disease Epidemiology Collaboration equation without race adjustment (CKD-EPI) (18). CKD was defined as eGFR $<60 \mathrm{~mL} / \mathrm{min} / 1.73 \mathrm{~m}^{2}$, or eGFR more than $60 \mathrm{ml} / \mathrm{min} / 1.73 \mathrm{~m}^{2}$ with albumin to creatinine ratio $($ ACR $)>2.5 \mathrm{mg} / \mathrm{mmol}$ (male) $>3.5 \mathrm{mg} / \mathrm{mmol}$ (female). Control participants enrolled had eGFR $>90 \mathrm{ml} / \mathrm{min}$ and ACR $<2.5$ $\mathrm{mg} / \mathrm{mmol}$ (male), $<3.5 \mathrm{mg} / \mathrm{mmol}$ (female). HIV viral load was examined at enrollment.

\section{HIV Viral Load}

Plasma HIVRNA quantitative analysis was assayed as previously reported by Tung et al. using the Roche Cobas Ampliprep/Taqman qRT-PCR assay, v. 3.1.2 Roche Diagnostics, Indianapolis, IN, USA (19). The test quantitates HIV RNA over the range of $20-10,000,000$ copies $/ \mathrm{mL}$.

\section{Genotyping of APOL1 G1-G2 Risk Variants}

APOL1 renal risk variants G1 (rs73885319, p.S342G and rs60910145, p.I384M) and G2 (rs71785313, p.N388_Y389del) were genotyped by custom TaqMan genotyping assays (Applied Biosystems, Foster City, CA) (20).

\section{Nucleic Acid Extraction and Quantitative PCR for JCV and BKV}

Frozen urine $(200 \mathrm{~mL})$ samples from the participants were thawed, and total nucleic acid was extracted. The extraction procedure used the Magna Pure LC, version 2.0, apparatus and Magna Pure LC total Nucleic Acid Isolation Kit Reagents 
TABLE 1 | Comparison of CKD patients and control.

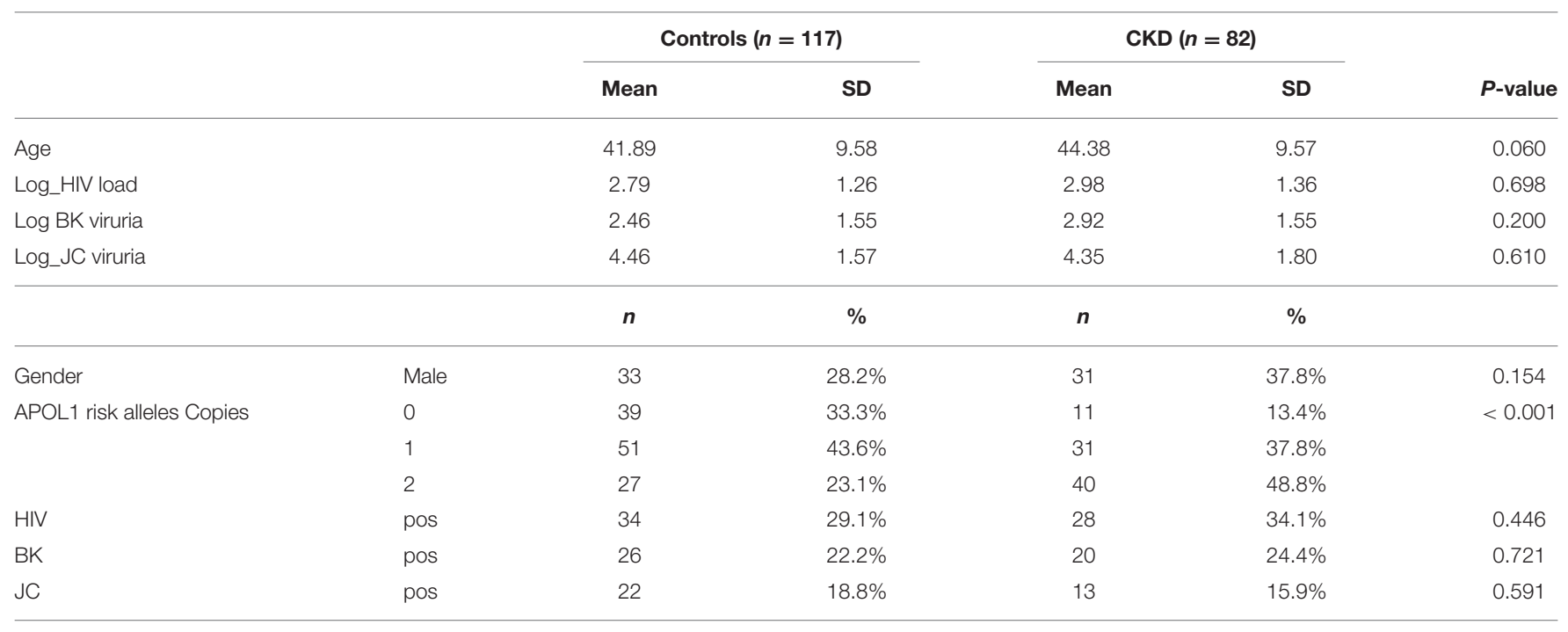

(Roche Diagnostics, Germany) according to the manufacturer's instructions (elution volume, $100 \mathrm{~mL}$ ).

\section{TaqMan Real Time PCR}

The primers and probes were derived from nucleotide sequences of the $\mathrm{N}$ terminus of the viral $\mathrm{T}$ antigen of JCV and BKV: JCV, $5^{\prime}$-GAGTGTTGGGATCCTGTGTTTT-3' (forward); $5^{\prime}$ -AGAagtgGgatgaAgACCTGTTT-3' (reverse); and Probe 5'FAM-TCATCACTGGCAAACATTTCTTCATGGC- BHQ1-3'; BKV: 5' -TTGCTTCTTCATCACTGGCAA-3' (forward); 5'-AGTCCTGGTGGAGTTCCTTTAATG-3' (reverse); and probe $5^{\prime}$ FAM-CATATCTTCATGGCAAAATAAATCTTCATCT CATCCCATTT-BHQ-1-3'.

The PCR reaction was performed in a total volume of 25 ul containing Absolute Blue quantitative PCR mix (Thermo Scientific, UK) in the presence of $10 \mathrm{~mL}$ target DNA, $300 \mathrm{nM}$ of each primer and $200 \mathrm{nM}$ of the probe. PCR was performed using the rotor gene 6000/Q instrument (Corbett Research/Qiagen, Hilden, Germany) under the following conditions: $15 \mathrm{~min}$ at $95^{\circ} \mathrm{C}$ and 45 cycles of $15 \mathrm{~s}$ at $95^{\circ} \mathrm{C}$ and $60 \mathrm{~s}$ at $60^{\circ} \mathrm{C}$. For quantitative results analysis, an average standard curve was constructed using quantified JCV and BKV DNA (Advanced Biotechnology Industry, $\mathrm{MD})$. The results are reported as the number of JCV/BKV genome copies per $1 \mathrm{~mL}$ of urine. The lowest detection level was 100 genomic copies per $1 \mathrm{~mL}$.

\section{Statistical Analysis}

Univariate analysis (Chi-squared test, $t$-test) was used to compare case and control groups. Multivariate logistic regression with stepwise, forward and backward model selection was used to predict the risks for HIV viral load, JC and BK viruria and CKD. Each covariate was corrected for all other variables. The covariates that were included for CKD were: age, gender, APOL1 RRA, BK viruria, JC viruria and HIV viremia. The interaction between APOL1 RRA and HIV viremia was added to the CKD risk association model. For CKD risk, we adjusted sequentially to four models: model 1: for APOL1 variants, age and sex, model 2: further adjusted for BK and JC viruria, model 3: as for model 2 plus HIV viremia and model 4: as for model 3 plus the interaction of APOL1 RRA and HIV viremia. For models predicting HIV viremia, JC and BK viruria, the following covariates were included in the logistic regression: age, gender, CKD, urine albumin/creatinine, APOL1 RRA and the other two viruses, respectively.

\section{RESULTS}

\section{Association With CKD}

The demographic and clinical characteristics for participants in this cohort, stratified by case-control status $(n=82, n=117$, respectively) are presented in Tables $\mathbf{1}, 2$. The CKD patient group and the control group did not differ significantly by age ( $p$ value $=0.06)$ or sex $(p$-value $=0.154)$ (Table 1$)$. We compared the distribution of G1 and G2 RRAs in HIV seroprevalent subjects with and without CKD. The following covariates were included: age, gender, APOL1 RRA, HIV viremia, BK viruria, JC viruria and the interaction of $\mathrm{HIV}^{*}$ APOL1 RRA. Multivariate logistic regression with a stepwise, forward and backward model selection showed that even a single APOL1 RRA was associated with CKD, OR 4.429 (95\% CI 1.49-13.15, $p=0.007)$. As expected, 2 APOL1 RRA were significantly associated with CKD, OR 12.6 (95\% CI 3.89-40.80, $p<0.0001$ ). HIV viremia was also associated with CKD, OR 7.45 (95\% CI 1.66-33.35, $p=0.009$ ). The interaction between APOL1 RRA and HIV was significant $(p=0.011)$, with OR 0.081 and 0.073 with 1 and 2 APOL1 RRA, respectively. This reverse association is perplexing and might be explained by Simpson's paradox, and does not seem to confer biological significance (21-23) (Table 3). Interestingly, adjusted models for age, sex, BK, JC and HIV viremia (models 2 and 3, respectively) did not change the association of 2 APOL RRA with CKD while adjustment for APOL1 RRA*HIV 
TABLE 2 | Demographic and clinical characteristics for individuals participating in this cohort, stratified by case-control status.

\begin{tabular}{|c|c|c|c|c|}
\hline \multicolumn{5}{|c|}{ Baseline demographic characteristics and clinical parameters } \\
\hline & \multicolumn{3}{|c|}{ HIV + Cases with CKD } & \multirow[b]{2}{*}{$\begin{array}{c}\text { APOL1 - } \\
2 \text { risk alleles (40) }\end{array}$} \\
\hline & $\begin{array}{c}\text { APOL1 - } \\
0 \text { risk alleles (11) }\end{array}$ & $\begin{array}{c}\text { APOL1 - } \\
1 \text { risk alleles (31) }\end{array}$ & $\begin{array}{c}\text { APOL1 - } \\
0+1 \text { risk alleles (42) }\end{array}$ & \\
\hline Age at enrollment, y & $\begin{array}{c}39.8 \\
(35.8-44.8)\end{array}$ & $\begin{array}{c}46.2 \\
(40.9-51.1)\end{array}$ & $\begin{array}{c}44.8 \\
(38.9-50.8)\end{array}$ & $\begin{array}{c}44.8 \\
(36.5-51.5)\end{array}$ \\
\hline Female sex, $n$ (\%) & 63.6 & 67.7 & 66.6 & 62.9 \\
\hline CKD-EPI eGFR, $\mathrm{mL} / \mathrm{min} / 1.73 \mathrm{~m}^{2}$ & $\begin{array}{c}42.7 \\
(20.1-51.2)\end{array}$ & $\begin{array}{c}36.8 \\
(22.3-56.2)\end{array}$ & $\begin{array}{c}39.3 \\
(20.6-54.9)\end{array}$ & $\begin{array}{c}18.6 \\
(11.6-42.3)\end{array}$ \\
\hline UACR, mg/mmol & $\begin{array}{c}1.5 \\
(0.5-2.4)\end{array}$ & $\begin{array}{c}2.79 \\
(0.99-10.7)\end{array}$ & $\begin{array}{c}2.26 \\
(0.94-6.25)\end{array}$ & $\begin{array}{c}3.2 \\
(0.7-64.9)\end{array}$ \\
\hline JC virus, \% & 9 & 22.5 & 19 & 12.5 \\
\hline $\log (\mathrm{JC} \text { titers })^{\mathrm{a}}$ & 2.78 & $\begin{array}{c}4.4 \\
(3.7-5.5)\end{array}$ & $\begin{array}{c}4.3 \\
(3.2-5.5)\end{array}$ & $\begin{array}{c}2.9 \\
(2.3-4.9)\end{array}$ \\
\hline BK virus, \% & 27.2 & 32.2 & 30.9 & 17.5 \\
\hline $\log (B K \text { titers })^{a}$ & $\begin{array}{c}1.27 \\
(1-1.9)\end{array}$ & $\begin{array}{c}3.8 \\
(2.4-4.6)\end{array}$ & $\begin{array}{c}3.3 \\
(1.2-4.6)\end{array}$ & $\begin{array}{c}2.3 \\
(1.8-3)\end{array}$ \\
\hline HIV virus, \% & 54.5 & 19.3 & 28.5 & 37.5 \\
\hline \multirow[t]{3}{*}{$\log (\text { HIV titers) })^{a}$} & $\begin{array}{c}1.6 \\
(1.5-3.6)\end{array}$ & $\begin{array}{c}3 \\
(1.9-4.2)\end{array}$ & $\begin{array}{c}2.2 \\
(1.5-4.3)\end{array}$ & $\begin{array}{c}3.2 \\
(2-4.3)\end{array}$ \\
\hline & \multicolumn{4}{|c|}{ HIV+ controls without CKD } \\
\hline & $\begin{array}{c}\text { APOL1 - } \\
0 \text { risk alleles (39) }\end{array}$ & $\begin{array}{c}\text { APOL1 - } \\
1 \text { risk alleles (51) }\end{array}$ & $\begin{array}{c}\text { APOL1 - } \\
0+1 \text { risk alleles (90) }\end{array}$ & $\begin{array}{c}\text { APOL1 - } \\
2 \text { risk alleles (27) }\end{array}$ \\
\hline Age at enrollment, y & $\begin{array}{c}39.2 \\
(33.9-47)\end{array}$ & $\begin{array}{c}38.9 \\
(34.6-49.9)\end{array}$ & $\begin{array}{c}39.1 \\
(34.2-49.8)\end{array}$ & $\begin{array}{c}43.9 \\
(38.2-48.8)\end{array}$ \\
\hline Female sex, $n(\%)$ & 76.9 & 72.5 & 74.4 & 62.9 \\
\hline CKD-EPI eGFR, $\mathrm{mL} / \mathrm{min} / 1.73 \mathrm{~m}^{2}$ & $\begin{array}{c}117.8 \\
(104.4-131.8)\end{array}$ & $\begin{array}{c}124.6 \\
(109-130.86)\end{array}$ & $\begin{array}{c}121.6 \\
(106.6-131.6)\end{array}$ & $\begin{array}{c}120 \\
(109.5-130.3)\end{array}$ \\
\hline UACR, $\mathrm{mg} / \mathrm{mmol}$ & $\begin{array}{c}0.6 \\
(0.5-1.2)\end{array}$ & $\begin{array}{c}0.6 \\
(0.4-1)\end{array}$ & $\begin{array}{c}0.6 \\
(0.4-1)\end{array}$ & $\begin{array}{c}0.7 \\
(0.5-1)\end{array}$ \\
\hline JC virus, \% & 17.9 & 25.5 & 22.2 & 7.4 \\
\hline $\log (\mathrm{JC} \text { titers })^{\mathrm{a}}$ & $\begin{array}{c}4.6 \\
(2.6-5.3)\end{array}$ & $\begin{array}{c}5.1 \\
(3.3-5.8)\end{array}$ & $\begin{array}{c}4.7 \\
(2.7-5.8)\end{array}$ & $\begin{array}{c}4.7 \\
(4.2-5.2)\end{array}$ \\
\hline BK virus, \% & 10.2 & 31.3 & 22.2 & 18.5 \\
\hline $\log (B K \text { titers })^{a}$ & $\begin{array}{c}1.5 \\
(1.1-1.6)\end{array}$ & $\begin{array}{c}2.6 \\
(1.2-3.7)\end{array}$ & $\begin{array}{c}2 \\
(1.1-3.5)\end{array}$ & $\begin{array}{c}1 \\
(1-3.1)\end{array}$ \\
\hline HIV virus, ${ }^{\mathrm{b}}$ & 15.3 & 27.4 & 22.2 & 51.84 \\
\hline Log (HIV titers) $)^{a}$ & $\begin{array}{c}2.5 \\
(2.3-2.8)\end{array}$ & $\begin{array}{c}2.2 \\
(1.5-2.8)\end{array}$ & $\begin{array}{c}2.2 \\
(1.6-2.9)\end{array}$ & $\begin{array}{c}3.2 \\
(1.7-4.8)\end{array}$ \\
\hline
\end{tabular}

Data presented as median (25th percentile to 75 th percentile) for continuous variables or \% for categorical variables.

CKD-EPI, Chronic Kidney Disease Epidemiology Collaboration.

${ }^{a}$ Data from subjects that have viremia or viruria measured.

${ }^{b}$ HIV viremia: more than 20 copies $/ \mathrm{ml}$.

interaction (model 4) increased the OR for 1 and 2 APOL1 RRA significantly (Table 4).

\section{Prevalence of HIV Viremia}

Participants with CKD (cases) and those without CKD (controls) were evaluated for HIV viral load, JCV and BKV viruria. All HIV-positive patients recruited from HIV clinics were likely to have been initiated on antiretroviral therapy (ART) before recruitment into the study. To determine whether APOL1
G1 or G2 RRAs affect host susceptibility to HIV viremia, multivariate logistic regression with a stepwise, forward and backward model selection was used to predict HIV viral load. Variables included in the model were age, gender, JC viruria, BK viruria, APOL1 RRA (2 vs. 1 vs. 0), CKD, e GFR and urine albumin to creatinine ratio. The two APOL1 RRA genotypes were associated with an increased probability of having HIV viremia OR 2.37 (95\% CI 1.0-5.63, $p=0.05$ ) (Table 5). Moreover, a higher viral load (more than 40,000 
TABLE 3 | Odds ratio (OR) and 95\% confidence intervals (Cls) for the association with CKD.

\begin{tabular}{lcc}
\hline & CKD OR (95\% CI) & P-value \\
\hline Age & $1.02(0.99-1.06)$ & 0.09 \\
Gender & $0.77(0.39-1.5)$ & 0.45 \\
APOL1 1 RRA & $4.42(1.491-13.158)$ & 0.007 \\
APOL1 2 RRA & $12.6(3.89-40.80)$ & $<0.0001$ \\
HIV viremia & $7.45(1.66-33.35)$ & 0.009 \\
BK viruria & $1.17(0.57-2.42)$ & 0.65 \\
JC viruria & $0.84(0.36-1.94)$ & 0.68 \\
APOL1 1 RRA* HIV viremia & 0.008 \\
APOL1 2 RRA & $0.081(0.01-0.52)$ & 0.005 \\
\hline
\end{tabular}

a APOL1 RRA interaction with HIV viremia.

copies/ml) was observed in patients with 2 RRA compared with 0, 1 RRA OR 7.583 (95\% CI 1.530-37.597, $p=0.013$ ). Interestingly, males were found to have a higher risk of HIV viral load compared to females $(>40,000 / \mathrm{ml}$; OR of 4.552, 95\% CI 1.1-18.829, $p=0.036$ ). While previous studies have pointed to reduced ART success in males, that only partially is attributable to reduced ART adherence in males compared to females (24), the current study does not include information about ART adherence that could potentially explain this difference.

\section{Association of BK and JC Viruria}

HIV viremia was associated with a significant effect on the probability of JC virus urine shedding, reducing the probability of JC viruria compared to individuals without HIV viremia OR 0.35 (95\% CI 0.12-0.98, $P=0.046$; Table 5). JC viruria did not differ between patients with CKD and controls ( $p$-value $=0.67$ ). In addition, subjects with APOL1 RRA who had JC viruria did not display a lower prevalence of CKD compared to individuals who did not have JC viruria $(p$-value $=0.692)$. BK viruria was not associated with CKD and HIV viremia ( $p$-value 0.65 and 0.503 , respectively). In light of previous publications about the inhibitory interaction between BK and JC viruria (25), we assessed this possibility. As we previously reported (14), there was no correlation between BK and JC viruria (Pearson correlation coefficient: $0.43, \mathrm{p}=0.23$ ).

\section{DISCUSSION}

In this genetic epidemiological study of HIV infected individuals living in Ghana and Nigeria (26), we observed an association between 2 APOL1 RRA and HIV viremia and CKD. Notably, there was a trend for increased CKD risk with one APOL1 RRA that was significantly increased after adjustment for APOL1 RRA*HIV viremia interaction. This increased risk is in keeping with the reported marginal association of HIVAN with 1 risk allele, in individuals of black African ancestry from South Africa (7). Similarly, previous studies have also reported a marginal effect of one APOL1 RRA (1, 2, 27, 28), suggesting that the possibility that an environment (HIV)-gene interaction may enhance the risk of $\mathrm{CKD}$, in carriers of one APOL1 RRA.
Therefore, HIV is a robust risk factor for kidney disease, that may potentiate the genetic risk, even in individuals with only one risk allele, into manifest kidney disease. Innate immune responses to viruses can drive APOL1 kidney disease in patients with APOL1 high-risk genotypes as was demonstrated in case series of collapsing glomerulopathy caused by therapeutic administration of interferon products and in patients infected with COVID-19 $(29,30)$. Interestingly, one APOL1 RRA in kidney allograft was associated with collapsing glomerulopathy in a patient infected with COVID-19 (30), suggesting that one APOL1 risk allele may confer a pathogenic role in diseases that share enhanced activation of the innate immune system. For completeness, we point out that in a combined interaction analysis, the interaction of HIV viremia and 2 APOL1 RRA was associated with decreased CKD risk. We consider this not to reflect a biological effect but rather a statistical effect that can occur in interaction analyses of separately contributory associations, termed Simpson's paradox, but still make note in case future biological or clinical research is warranted to explain this result (21-23).

In addition, we demonstrate a complex interaction of HIV viremia with polyoma virus urine shedding. The increased HIV viral load was associated with reduced JC viruria, while BK viruria was not associated with CKD or HIV viremia. We did not demonstrate the protective association of JC viruria with preserved kidney function, as previously reported in patients who did not have HIV infection and had non-diabetic as well as diabetic kidney disease (12-14). We reasoned that in the presence of HIV viremia, the secretion of inflammatory cytokines, such as Interferon itself, might lead to restriction of other viruses, including suppression of JC viruria and thereby mask any such association.

The role of APOL1 as a member of the innate immune system is only partially understood. APOL1 has a wellcharacterized protective role that restores trypanolysis activity against Trypanosoma brucei rhodesiense (G2) and confers protection from active illness caused by Trypanosoma brucei gambiense (G1) (1, 4-6). It is not clear if APOL1 has broader protective roles as an innate immunity protein. Most interestingly, a recent analysis of the African-American participants of the Reasons for Geographic and Racial Differences in Stroke (REGARDS) study, demonstrated that APOL1 RRA were associated with sepsis risk under dominant [Hazard Ratio (HR) 1.55, 95\% confidence interval (CI), 1.13-2.11] and additive (HR per variant allele copy 1.25 , 95\% CI, 1.02-1.53) genetic models adjusted for covariates and ancestry, suggesting a complex interaction between $A P O L 1$ and general risk for severe infection (31). In contrast to the increased sepsis risk, some in vitro studies have demonstrated that APOL1 restricts HIV infectivity and protects human keratinocytes from the lethal effect of the Staphylococcus aureus $\alpha$ toxin $(8,9,32)$. Specifically, impaired HIV restriction in podocytes by the APOL1 encoded by RRA, has been suggested (10). However, an epidemiological study did not detect an association between HIV viral load and APOL1 variants. The ALIVE cohort revealed no evidence of association of APOL1 RRA with HIV infection acquisition, viral load or disease progression, in ART naïve patients (11). In contrast, the current study of ART treated patients points to 
TABLE 4 | Odds ratio (OR) and 95\% confidence intervals (Cls) for the association between APOL1 risk genotype and CKD.

\begin{tabular}{lcccc}
\hline APOL RRA & $\begin{array}{c}\text { Model 1, OR } \\
(\mathbf{9 5 \%} \mathbf{~ C l})\end{array}$ & $\begin{array}{c}\text { Model 2, OR } \\
(\mathbf{9 5 \%} \mathbf{~ C l})\end{array}$ & $\begin{array}{c}\text { Model 3, OR } \\
\mathbf{( 9 5 \% ~ C l )}\end{array}$ & $\begin{array}{c}\text { Model 4, OR } \\
\mathbf{( 9 5 \% ~ C l )}\end{array}$ \\
\hline 1 & $2.07(0.92-4.66)$ & $2.03(0.89-4.63)$ & $2.03(0.89-4.63)$ & $4.42(1.49-13.15)$ \\
2 & $5(2.17-11.547)$ & $4.96(2.15-11.46)$ & $4.96(2.15-11.46)$ & $12.6(3.89-40.8)$ \\
\hline
\end{tabular}

Multivariate logistic regression with stepwise and forward model selection was used to predict the risk for CKD. The explanatory variable is number of APOL 1 risk alleles: model 1 , adjusted for age and sex; model 2, further adjusted for JC and BK viruria; model 3 further adjusted for HIV viremia, model 4 further adjusted for APOL1 RRA* HIV interaction.

TABLE 5 | Odds ratio (OR) and 95\% confidence intervals (Cls) for the association with JC and BK viruria and HIV viremia.

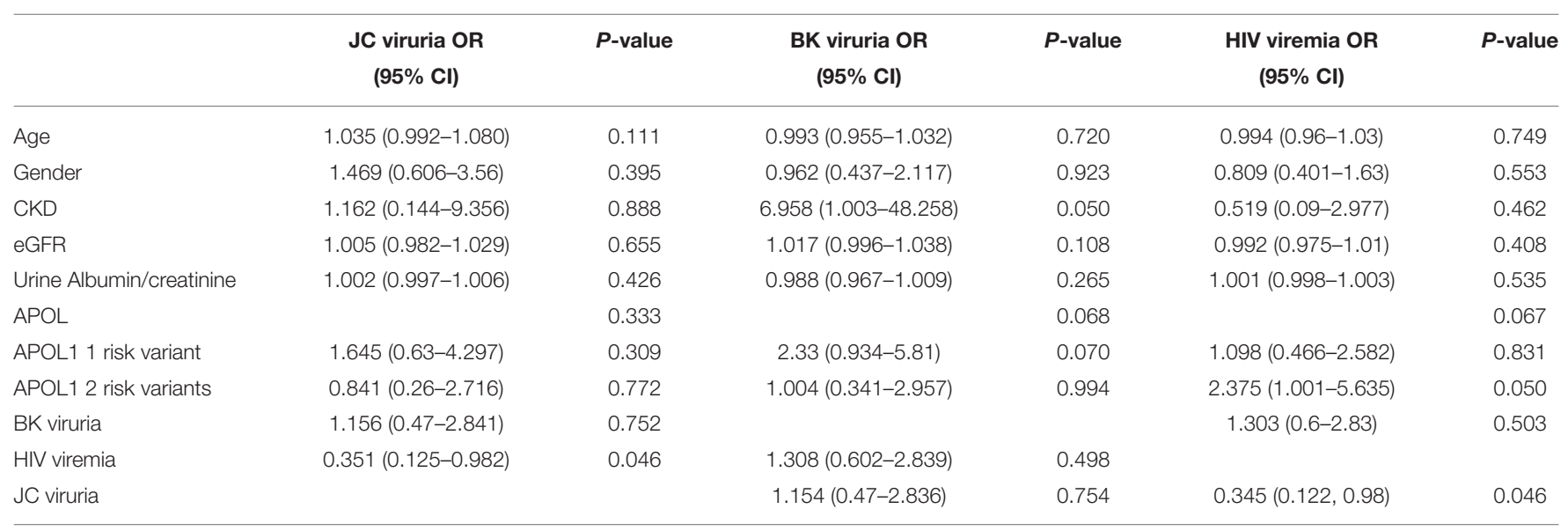

increased risk for HIV viremia in association with certain APOL1 genotypes. In accordance to the World Health Organization and International Antiviral Society-USA Panel recommendations from 2015 for early ART initiation regardless of CD4 cellcount (33), all participants were likely to have received ART, but we cannot confirm adherence. To the best of our knowledge, this is the first observed significant association between APOL1 risk variants and HIV viremia in patients receiving ART. The complex interaction between virus, host, treatment status and environmental factors may explain this association in contrast to previous publications. The dominant HIV subtype is different in West Africa vs. South Africa and the Americas (CRF02_AG, subtype $\mathrm{G}$ vs. $\mathrm{C}$ and $\mathrm{B}$, respectively) $(34,35)$. Different subtypes may have different biological properties resulting in differences in transmissibility and pathogenicity. In addition, the participants of the current cohort were treated with ART although adherence was not established. This is in contrast to the ALIVE cohort that was a prospective longitudinal natural cohort originally designed to characterize the incidence and natural history of HIV infection. Moreover, in the ALIVE study, viral loads not reflecting the steady-state (viral load measurements exceeding 3fold from the average of all remaining points) were excluded (11), thereby, reducing the probability of detecting transient viremia. Given the absence of longitudinal follow up in our cohort, we cannot determine whether the viremia detected was transient. In addition, we do not have data about CD4 cell count in parallel with HIV viral load. Similarly, we cannot determine whether these findings impact clinical outcomes, such as incidence of CKD as well as other HIV outcomes.
We demonstrate complex interactions between HIV viremia, $\mathrm{CKD}$ and polyoma viruria. Previous studies reported reduced JC viruria in CKD patients (12-14). Herein, reduced JC viruria was driven by HIV viremia and not CKD. We postulated that the reduced JC viruria in kidney disease and the presence of HIV viremia share similar signaling pathways that enhance the activation of the innate immune system. Enhanced inflammatory signaling (e.g., via the type I interferon signaling cascade that abrogates JC replication) restricts JCV growth and leads to decreased shedding of JCV $(14,36)$. Indeed, in vitro studies have demonstrated divergent interaction between IFN- $\beta$ and the two polyoma viruses. IFN- $\beta$ controls JCV replication but fails to restrict BKV (36), thereby, explaining the specific restriction of JC virus shedding in urine and not BK in patients with HIV viremia. We hypothesize that absence of JC viruria is an epiphenomenon, serving as a biomarker that reflects innate immune system activation. In contrast to JC viruria, only BK viruria is enhanced in immunocompromised patients with HIV infection and correlates inversely with the CD4+ cell count (1517). In the current cohort, BK viruria was not associated with CKD and HIV viremia. Most BK virus associated nephropathy occurs in renal allograft patients after kidney transplantation. However, some case reports have described BK virus-associated nephropathy in the native kidney, particularly in patients with human immunodeficiency virus infection (37, 38). Further studies are needed to explore the role of BK viruria in $\mathrm{CKD}$ patients infected with HIV.

The present study has limitations: This cohort has a relatively small sample size. HIV viral load was measured only at 
enrollment, so we could not determine if the enhanced viral load was transient or persistent. Similarly, we do not have information about CD4 cells count, ART compliance and longitudinal clinical outcomes of kidney function were missing. Therefore, we could not ascertain if the increased HIV viremia will translate to faster CKD progression, as was previously demonstrated (39). In addition, JC and BK viruria may fluctuate and was measured at a single time point over time in the current study.

In conclusion, this population genetic study demonstrates an increased risk for HIV viremia and CKD in patients with one and two APOL1 renal risk alleles. The association of one APOL1 risk allele with $\mathrm{CKD}$ suggests that if $\mathrm{G} 0$ has a protective role, it does not have complete suppressive penetrance; alternatively, this finding is also consistent with a gain of injury mechanism mediating kidney injury in individuals with a robust environmental insult, such as HIV infection. Future studies are warranted to explore the complex interaction of APOL1 RRA, CKD risk, HIV viremia and urine shedding of polyoma viruses. Confirmation in future studies of an association between two APOL1 risk alleles with HIV viremia and CKD would have significant therapeutic implications regarding APOL1 inhibition in patients with two risk alleles, who do not reside in Trypanosoma endemic areas.

\section{DATA AVAILABILITY STATEMENT}

The original contributions presented in the study are included in the article/supplementary material, further inquiries can be directed to the corresponding author/s.

\section{ETHICS STATEMENT}

The studies involving human participants were reviewed and approved by University of Ghana (Ghana Health Service Ethics

\section{REFERENCES}

1. Genovese G, Friedman DJ, Ross MD, Lecordier L, Uzureau P, Freedman BI, et al. Association of trypanolytic ApoL1 variants with kidney disease in African Americans. Science. (2010) 329:841-5. doi: 10.1126/science.1193032

2. Kopp JB, Nelson GW, Sampath K, Johnson RC, Genovese G, An $\mathrm{P}$, et al. APOL1 genetic variants in focal segmental glomerulosclerosis and HIV-associated nephropathy. J Am Soc Nephrol. (2011) 22:212937. doi: 10.1681/ASN.2011040388

3. Tzur S, Rosset S, Shemer R, Yudkovsky G, Selig S, Tarekegn A, et al. Missense mutations in the APOL1 gene are highly associated with end stage kidney disease risk previously attributed to the MYH9 gene. Hum Genet. (2010) 128:345-50. doi: 10.1007/s00439-010-0861-0

4. Thomson R, Genovese G, Canon C, Kovacsics D, Higgins MK, Carrington M, et al. Evolution of the primate trypanolytic factor APOL1. Proc Natl Acad Sci USA. (2014) 111:E2130-9. doi: 10.1073/pnas.1400699111

5. Cooper A, Ilboudo H, Alibu VP, Ravel S, Enyaru J, Weir W, et al. APOL1 renal risk variants have contrasting resistance and susceptibility associations with African trypanosomiasis. Elife. (2017) 6:e25461. doi: 10.7554/eLife.25461.022

6. Kruzel-Davila E, Skorecki K. The double-edged sword of evolution. Elife. (2017) 6:e29056. doi: 10.7554/eLife.29056
Review Committee). The patients/participants provided their written informed consent to participate in this study.

\section{AUTHOR CONTRIBUTIONS}

EK-D, BMS, AG, AN, GA, BLS, AO, DA, and KS contributed to conception and design of the study. AG, AN, and GA supervised the study. IU, YR, VB, CO, MMat, TO, SAj, MMam, VB, SAn, AA, JP-R, VMA, and FA enrolled patients. EK-D, BMS, and DA organized the database. EK-D, KS, BMS, CW, AO, and DA wrote the draft of the manuscript. MC performed the polyoma viruses analysis. SAg performed the HIV viral load analysis. AR and $\mathrm{BH}$ performed the statistical analysis. BMS, EA-A, PA, and $\mathrm{CW}$ performed the genotype analysis. All authors contributed to manuscript revision, read, and approved the submitted version.

\section{FUNDING}

This study was supported by the following grants from NIH/NHGRI/NIDD, H3Africa Kidney Disease Research Network (U54 HG006939) a Wellcome/African Academy of Sciences DELTAS Africa grant (DEL-15-007: Awandare) and World Bank ACE grant (ACE02-WACCBIP: Awandare). Supported by a grant from the Israel Science Foundation to KS (grant 3757/20) and by the Kaylie Family Foundation Kidney Disease Research Center. This project has been funded in whole or in part with federal funds from the National Cancer Institute, National Institutes of Health, under contract HHSN26120080001E. The content of this publication does not necessarily reflect the views or policies of the Department of Health and Human Services, nor does mention of trade names, commercial products, or organizations imply endorsement by the U.S. Government. This Research was supported [in part] by the Intramural Research Program of the NIH, National Cancer Institute, Center for Cancer Research.

7. Kasembeli AN, Duarte R, Ramsay M, Mosiane P, Dickens C, Dix-Peek $\mathrm{T}$, et al. APOL1 risk variants are strongly associated with HIV-associated nephropathy in Black South Africans. J Am Soc Nephrol. (2015) 26:288290. doi: 10.1681/ASN.2014050469

8. Taylor HE, Khatua AK, Popik W. The innate immune factor apolipoprotein L1 restricts HIV-1 infection. J Virol. (2014) 88:592-603. doi: 10.1128/JVI.02828-13

9. McLaren PJ, Gawanbacht A, Pyndiah N, Krapp C, Hotter D, Kluge SF, et al. Identification of potential HIV restriction factors by combining evolutionary genomic signatures with functional analyses. Retrovirology. (2015) 12:41. doi: 10.1186/s12977-015-0165-5

10. Mikulak J, Oriolo F, Portale F, Tentorio P, Lan X, Saleem MA, et al. Impact of APOL1 polymorphism and IL-1beta priming in the entry and persistence of HIV-1 in human podocytes. Retrovirology. (2016) 13:63. doi: 10.1186/s12977-016-0296-3

11. An P, Kirk GD, Limou S, Binns-Roemer E, Kopp JB, Winkler CA. Impact of APOL1 genetic variants on HIV-1 infection and disease progression. Front Immunol. (2019) 10:53. doi: 10.3389/fimmu.2019.00053

12. Divers J, Nunez M, High KP, Murea M, Rocco MV, Ma L, et al. JC polyoma virus interacts with APOL1 in African Americans with nondiabetic nephropathy. Kidney Int. (2013) 84:1207-13. doi: 10.1038/ki.2013.173 
13. Freedman BI, Kistler AL, Skewes-Cox P, Ganem D, Spainhour M, Turner J, et al. JC polyoma viruria associates with protection from chronic kidney disease independently from apolipoprotein L1 genotype in African Americans. Nephrol Dial Transplant. (2018) 33:1960-7. doi: 10.1093/ndt/gfx368

14. Kruzel-Davila E, Divers J, Russell GB, Kra-Oz Z, Cohen MS, Langefeld CD, et al. JC viruria is associated with reduced risk of diabetic kidney disease. J Clin Endocrinol Metab. (2019) 104:2286-94. doi: 10.1210/jc.2018-02482

15. Knowles WA, Pillay D, Johnson MA, Hand JF, Brown DW. Prevalence of longterm BK and JC excretion in HIV-infected adults and lack of correlation with serological markers. J Med Virol. (1999) 59:474-9. doi: 10.1002/(SICI)10969071(199912)59:4<474::AID-JMV9>3.0.CO;2-W

16. Markowitz RB, Thompson HC, Mueller JF, Cohen JA, Dynan WS. Incidence of BK virus and JC virus viruria in human immunodeficiency virus-infected and -uninfected subjects. J Infect Dis. (1993) 167:1320. doi: 10.1093/infdis/167.1.13

17. Behzad-Behbahani A, Klapper PE, Vallely PJ, Cleator GM, Khoo SH. Detection of BK virus and JC virus DNA in urine samples from immunocompromised (HIV-infected) and immunocompetent (HIV-non-infected) patients using polymerase chain reaction and microplate hybridisation. J Clin Virol. (2004) 29:224-9. doi: 10.1016/S1386-6532(03)00155-0

18. Levey AS, Stevens LA, Schmid CH, Zhang YL, Castro AF, 3rd, Feldman HI, et al. A new equation to estimate glomerular filtration rate. Ann Intern Med. (2009) 150:604-12. doi: 10.7326/0003-4819-150-9-200905050-00006

19. Tung YC, Ke LY, Lu PL, Lin KH, Lee SC, Lin YY, et al. Comparison of the Roche COBAS AmpliPrep/COBAS TaqMan HIV-1 test v1.0 with v2.0 in HIV-1 viral load quantification. Kaohsiung J Med Sci. (2015) 31:18893. doi: 10.1016/j.kjms.2014.12.010

20. David VA, Binns-Roemer EA, Winkler CA. Taqman assay for genotyping CKD-associated APOL1 SNP rs60910145: a cautionary note. Kidney Int Rep. (2019) 4:184-5. doi: 10.1016/j.ekir.2018.09.018

21. Heydtmann M. The nature of truth: Simpson's Paradox and the limits of statistical data. QJM. (2002) 95:247-9. doi: 10.1093/qjmed/95.4.247

22. Chipman J, Braun D. Simpson's paradox in the integrated discrimination improvement. Stat Med. (2017) 36:4468-81. doi: 10.1002/sim.6862

23. Julious SA, Mullee MA. Confounding and Simpson's paradox. BMJ. (1994) 309:1480-1. doi: 10.1136/bmj.309.6967.1480

24. Boulle C, Kouanfack C, Laborde-Balen G, Boyer S, Aghokeng AF, Carrieri $\mathrm{MP}$, et al. Gender differences in adherence and response to antiretroviral treatment in the stratall trial in rural district hospitals in Cameroon. J Acquir Immune Defic Syndr. (2015) 69:355-64. doi: 10.1097/QAI.00000000000 00604

25. Cheng XS, Bohl DL, Storch GA, Ryschkewitsch C, Gaudreault-Keener $\mathrm{M}$, Major EO, et al. Inhibitory interactions between BK and JC virus among kidney transplant recipients. J Am Soc Nephrol. (2011) 22:82531. doi: 10.1681/ASN.2010080877

26. Osafo C, Raji YR, Burke D, Tayo BO, Tiffin N, Moxey-Mims MM, et al. Human heredity and health (H3) in Africa kidney disease research network: a focus on methods in Sub-Saharan Africa. Clin J Am Soc Nephrol. (2015) 10:2279-87. doi: 10.2215/CJN.11951214

27. Kanji Z, Powe CE, Wenger JB, Huang C, Ankers E, Sullivan DA, et al. Genetic variation in APOL1 associates with younger age at hemodialysis initiation. $J$ Am Soc Nephrol. (2011) 22:2091-7. doi: 10.1681/ASN.2010121234

28. Tzur S, Rosset S, Skorecki K, Wasser WG. APOL1 allelic variants are associated with lower age of dialysis initiation and thereby increased dialysis vintage in African and Hispanic Americans with non-diabetic end-stage kidney disease. Nephrol Dial Transplant. (2012) 27:1498505. doi: 10.1093/ndt/gfr796

29. Nichols B, Jog P, Lee JH, Blackler D, Wilmot M, D'Agati V, et al. Innate immunity pathways regulate the nephropathy gene Apolipoprotein L1. Kidney Int. (2015) 87:332-42. doi: 10.1038/ki.2014.270
30. Shetty AA, Tawhari I, Safar-Boueri L, Seif N, Alahmadi A, Gargiulo R, et al. COVID-19-Associated glomerular disease. J Am Soc Nephrol. (2021) 32:33-40. doi: 10.1681/ASN.20200 60804

31. Chaudhary NS, Moore JX, Zakai NA, Judd SE, Naik RP, Limou S, et al. APOL1 nephropathy risk alleles and risk of sepsis in blacks. Clin J Am Soc Nephrol. (2019) 14:1733-40. doi: 10.2215/CJN.04490419

32. Brauweiler AM, Goleva E, Leung DY. Interferon-? Protects from Staphylococcal alpha toxin-induced keratinocyte death through apolipoprotein L1. J Invest Dermatol. (2016) 136:65864. doi: 10.1016/j.jid.2015.12.006

33. Gunthard HF, Saag MS, Benson CA, del Rio C, Eron JJ, Gallant JE, et al. Antiretroviral drugs for treatment and prevention of HIV infection in adults: 2016 recommendations of the international antiviral society-USA panel. JAMA. (2016) 316:191-210. doi: 10.1001/jama.2016.8900

34. Hemelaar J, Gouws E, Ghys PD, Osmanov S. Global trends in molecular epidemiology of HIV-1 during 2000-2007. AIDS. (2011) 25:679-89. doi: 10.1097/QAD.0b013e328342ff93

35. Hemelaar J, Elangovan R, Yun J, Dickson-Tetteh L, Fleminger I, Kirtley S, et al. Global and regional molecular epidemiology of HIV-1, 1990-2015: a systematic review, global survey, and trend analysis. Lancet Infect Dis. (2019) 19:143-55. doi: 10.1016/S1473-3099(18)30647-9

36. Assetta B, De Cecco M, O'Hara B, Atwood WJ. JC polyomavirus infection of primary human renal epithelial cells is controlled by a type I IFN-induced response. MBio. (2016) 7:e00903-16. doi: 10.1128/mBio.00903-16

37. Crum-Cianflone N, Quigley M, Utz G, Hale B. BK virusassociated renal failure among HIV patients. AIDS. (2007) 21:1501-2. doi: 10.1097/QAD.0b013e32823647d4

38. Jung SW, Sung JY, Park SJ, Jeong KH. BK virus-associated nephropathy with hydronephrosis in a patient with AIDS: a case report and literature review. Clin Nephrol. (2016) 85:173-8. doi: 10.5414/CN108482

39. Estrella MM, Li M, Tin A, Abraham AG, Shlipak MG, Penugonda S, et al. The association between APOL1 risk alleles and longitudinal kidney function differs by HIV viral suppression status. Clin Infect Dis. (2015) 60:646-52. doi: 10.1093/cid/ciu765

Conflict of Interest: KS - Inventor on patent USTPO 77864 entitled: Methods and Kits for Determining Predisposition to Kidney Disease.

The remaining authors declare that the research was conducted in the absence of any commercial or financial relationships that could be construed as a potential conflict of interest.

Publisher's Note: All claims expressed in this article are solely those of the authors and do not necessarily represent those of their affiliated organizations, or those of the publisher, the editors and the reviewers. Any product that may be evaluated in this article, or claim that may be made by its manufacturer, is not guaranteed or endorsed by the publisher.

Copyright (c) 2021 Kruzel-Davila, Sankofi, Kubi Amos-Abanyie, Ghansah, Nyarko, Agyemang, Awandare, Szwarcwort-Cohen, Reiner-Benaim, Hijazi, Ulasi, Raji, Boima, Osafo, May Adabayeri, Matekole, Olanrewaju, Ajayi, Mamven, Antwi, Ademola, Plange-Rhule, Arogundade, Akyaw, Winkler, Salako, Ojo, Skorecki, Adu and the H3Africa Kidney Disease Research Network Investigators. This is an openaccess article distributed under the terms of the Creative Commons Attribution License (CC BY). The use, distribution or reproduction in other forums is permitted, provided the original author(s) and the copyright owner(s) are credited and that the original publication in this journal is cited, in accordance with accepted academic practice. No use, distribution or reproduction is permitted which does not comply with these terms. 